\title{
ARBORIZAÇÃO: DESAFIOS EM COMUNIDADE DO SEMIÁRIDO BRASILEIRO
}

\section{AFFORESTATION: CHALLENGE IN RURAL COMMUNITY OF THE SEMIÁRID OF PARAIBA}

\author{
Joedla Rodrigues de Lima ${ }^{1}$, Roberta Patrícia de Sousa ${ }^{2}$, Geovânio Alves ${ }^{3}$, Luan Figuerôa ${ }^{4}$,
Elisabeth de Oliveira
}

\section{RESUMO}

A arborização traz vários benefícios ao ambiente natural ou urbanizado, tais como, atenuação do microclima, do barulho, interceptação das gotículas de chuva. O processo de urbanização diminui as áreas verdes e alteram o microclima local. Diante disto, o objetivo desse trabalho é identificar a percepção de uma comunidade em relação à importância da arborização em torno de suas moradias. Entrevistou-se formalmente 27 famílias, da comunidade quilombola "Serra Feia", no semiárido brasileiro. $\mathrm{Na}$ opinião dos entrevistados, as árvores proporcionam sombra, flores e frutos, mas alegam dificuldades financeiras para adquiri-las, a escassez de água para irriga-las e a presença de animais soltos que as destroem. Citaram duas espécies arbóreas como as preferidas para o plantio: nin-indiano (Azadirachta indica A. Juss) e a mangueira (Mangifera indica Linn). A partir da observação direta verificou-se que a comunidade não possui pavimentação nas ruas e acima de $80 \%$ delas não tem calçadas, a área apresenta rochosidade e o solo é predominantemente raso, argiloso e compactado, condições que exigem escolha criteriosa dos locais para o plantio de mudas.

Palavras-chave: Caatinga; Percepção; Questionário estruturado

\section{ABSTRACT}

The afforestation brings several benefits to the natural or urbanized environment, some of them are microclimate and noise attenuation and rain drops interception. The process of urbanization reduces the green areas and alters the local microclimate. Therefore, the objective of this article is to identify the perception of a community regarding the afforestation around their habitations. We formally interviewed 27 families of the quilombola community "Serra Feia" in the Brazilian semiarid. In the interviewees' point of view, the trees provide shadow, flowers and fruits, but they complain about the financial difficulties of acquiring them, the water shortage and the presence of untied animals that destroy the trees place. They demonstrated preference for two species to cultivate: Indian lilac (Azadirachta indica A. Juss) and the mango tree (Mangifera indica Linn). After direct observation, we verified that the community has no paved streets and more than $80 \%$ of them have no sidewalks, the soil in the area is rocky and predominantly shallow, clayey and compacted, conditions that require judicious selection of the seedlings planting places.

Keywords: Caatinga; Perception; Structured questionnaire.

\footnotetext{
Recebido em 01.11.2017 e aceito em 14.03.2018

1 Engenheira Agrícola. Doutora. Professora Associada da Universidade Federal de Campina Grande. Patos/PB. Email: joedlalima@Yahoo.com.br

2 Graduanda de Engenharia Florestal. Universidade Federal de Campina Grande. Patos/PB. Email: robertapatríciasousa@hotmail.com

3 Graduando de Engenharia Florestal. Universidade Federal de Campina Grande.Patos/PB. Email: geovanio_alves1@hotmail.com

4 Graduando de Engenharia Florestal. Universidade Federal de Campina Grande. Patos/PB. Email: luan.figueroa@hotmail.com

5 Engenharia Florestal. Doutora. Professora Titular da Universidade Federal de Campina Grande. Patos/PB. Email: betholiveira12@gmail.com
} 


\section{INTRODUÇÃO}

$\mathrm{Na}$ atualidade, é imprescindível a consciência que a arborização traz vários benefícios ao ambiente natural ou urbanizado, pois as árvores absorvem grande quantidade de energia na faixa do infravermelho médio $(1,3$ a 2,6 $\mu \mathrm{m})$ que é utilizada para seus processos biológicos, com isto liberam menos calor no entorno. Leal, Biondi e Batista (2014) observaram que diferentes tipologias de florestas urbanas provocaram quebras na continuidade das altas temperaturas na cidade de Curitiba/PR, demonstrando a importância dos espaços verdes. Carielo (2012), destaca que a arborização também favorece o embelezamento do ambiente, a sensação de vivacidade, abrigo e alimento à fauna, sombra e purificação do ar.

Acrescenta-se, do ponto de vista da engenharia da arborização, a minimização da erosão eólica, pois as árvores agem como quebra ventos e as raízes auxiliam tanto na infiltração da água, quanto "agarram" o solo na sua área de abrangência (CRUZ, 2013).

No processo de urbanização ou para implantar atividades agropecuárias, desmata-se extensas áreas, geralmente sem atenção à necessária reposição arbórea, permitindo-se que preponderem os efeitos danosos advindos do solo descoberto, por exemplo, alteração do ciclo da água na área, aquecimento do solo. No semiárido brasileiro, as consequências são agravadas devido às suas características edafoclimáticas: os longos períodos de estiagem, a predominância de solos rasos e pedregosos.

As ações antrópicas, notadamente as atividades primárias de agricultura, pecuária, caça e pesca, que são ações necessárias para sobrevivência do ser humano, ocorrem predominantemente dentro de uma lógica exploratória intensa e respondem pelo quadro de degradação ambiental. Conhecer estas interações e como são percebidas pelos atores sociais é imprescindível para abalizar as ações que visem a melhoria ambiental destas comunidades.

Neste sentido, os estudos de percepção, que trata da forma como o indivíduo observa e interpreta o ambiente que o cerca, utilizando crenças pessoais e sendo influenciado por fatores culturais, educacionais, sociológicos e ambientais, pois "de acordo com a percepção que possui, o indivíduo direciona suas escolhas de vida" (OLIVEIRA; CORONA, 2008).

Diante da importância do processo de arborização e as ações antrópicas relacionadas ao desmatamento, seria possível avaliar a importância do processo de arborização de uma dada comunidade rural em situação de risco socioeconômico, considerando que há uma estreita relação entre o cotidiano destas pessoas e o ambiente natural? Diante do perfil obtido pode-se auxiliar no plantio de mudas, optando por espécies que valorizam e buscando um equilíbrio entre as espécies, pois a manutenção das mudas depende diretamente do interesse e do envolvimento de cada indivíduo. 
Este trabalho tem como objetivo identificar o perfil e os condicionantes físicos de uma comunidade quanto à arborização em torno de suas moradias. A escolha da comunidade quilombola "Serra Feia" deve-se a conjunção de alguns fatores, o isolamento geográfico, pois situa-se em região de serras, no limite entre as sub-bacias hidrográficas do Piranhas-açu e Taperoá, no estado da Paraíba; está sujeita às condições edafoclimáticas características do semiárido; segundo o Índice de Priorização Tecnológica (IPT) é considerada uma comunidade com "vulnerabilidade extremamente alta" (MEDEIROS et al., 2015) e a ausência de estudos deste teor.

Antes de propor qualquer alteração nas condições ambientais de uma comunidade é imprescindível verificar seu nível de interesse, incômodo ou satisfação em relação à questãofoco para assim sugerir ou gerenciar o processo de mudança.

\section{MATERIAL E MÉTODOS}

\section{Caracterização da área de estudo}

A comunidade de remanescentes quilombolas Serra Feia, localiza-se no distrito de São Sebastião, município de Cacimbas, sertão Paraibano, situada na Latitude Sul 07011'48,65" e Longitude Oeste $37^{\circ} 8^{\prime} 23,25$ ", altitude de 873 m (Figura 1). Em termos hidroclimáticos, esta comunidade está inserida na sub-bacia hidrográfica do rio Taperoá que desagua na bacia hidrográfica do rio Paraíba.

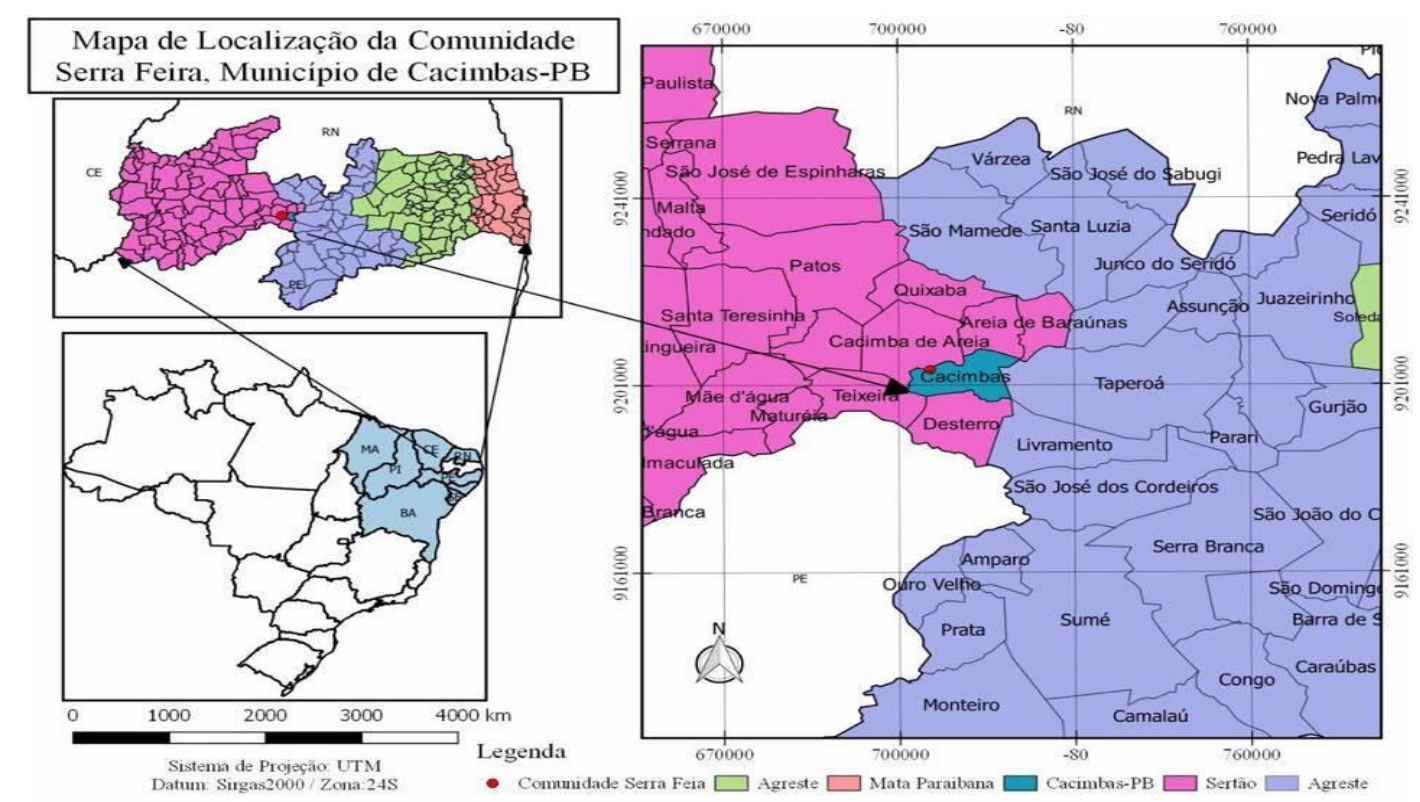

Figura 1. Mapa de localização da comunidade Serra Feia, Município de Cacimbas - PB

Figure 1. Location map of the community Serra Feia, Municipality of Cacimbas - PB 
O município de Cacimbas, situa na região centro-oeste do estado da Paraíba, Mesoregião sertão paraibano e microrregião Serra de Teixeira. Fisiograficamente, se insere no Polígono das Secas. Especificamente, na localização da comunidade em estudo, possui clima 4aTh Tropical quente de seca acentuada, com 7 a 8 meses secos, as chuvas se concentram de janeiro a abril. A vegetação é do tipo caatinga hiperxerófila, relevo varia de ondulado a fortemente ondulado. A temperatura média é de $24^{\circ} \mathrm{C}$. Os solos predominantes são os litólicos eutróficos e os cambissolos eutróficos, textura argilosa (CPRM, 2005).

Segundo o Censo Demográfico realizado, em 2010, pelo Instituto Brasileiro de Geografia e Estatística - IBGE (2015), o município de Cacimbas apresenta Índice de Desenvolvimento Humano (IDH) de 0,523.

\section{Procedimento de coleta dos dados}

A metodologia se baseia em estudo de caso, conforme Apolinário (2009), corresponde a uma investigação qualitativa obtido em situações reais em que o objeto de estudo é analisado em seu próprio contexto. A coleta dos dados pertinentes à percepção e arborização, ocorreu no mês de junho de 2015. Utilizou-se como métodos a observação ativa, o emprego de entrevista e a opinião de pesquisadores sobre as condições encontradas na área e suas considerações. A partir dos dados coletados e de sua análise, construiu-se algumas ações notadamente no âmbito da educação ambiental e arborização.

Foram entrevistadas 57 famílias de forma aleatória e voluntária. As residências foram visitadas e as que contavam com a presença de morador que aceitou prestar as informações, sendo este o representante da família presente no ambiente residencial e com idade acima de 16 anos, mantendo-se o anonimato. Segundo informações disponíveis na Rede internacional de computadores sobre o Projeto Cooperar, do Governo do Estado da Paraíba, são beneficiadas 175 famílias na comunidade quilombola Serra Feia, portanto a pesquisa abrangeu $32,6 \%$ das famílias cadastradas.

A definição do tamanho amostral, baseou-se em Rocha (1997), utilizando-se a equação $n=3,841 \cdot N \cdot 0,25 /\left((0,1)^{2} \cdot(N-1)+3,841 \cdot 0,25\right)$, onde: $n=$ número de amostras a realizar; $\mathrm{N}$ = número total de entrevistados; 3,841 = valor tabelado do Qui-Quadrado; 0,25 = variância máxima para desvio padrão igual a 0,5. Será considerando o erro amostral igual a 10,7\%, definindo assim, uma população amostral de 63 famílias para serem entrevistados. 
As entrevistas foram norteadas por um questionário semiestruturado (APPOLINÁRIO, 2009), preenchido pelos próprios pesquisadores, que desempenhava a função de facilitador sem interferir na resposta, inclusive pela pouca familiaridade do entrevistado com o processo de preenchimento dos dados. O questionário foi dividido em duas partes (Figura 2), a primeira com informações socioeconômicas da família e a segunda parte investigou-se a opinião sobre arborização. Nas dez questões sobre arborização, verificou-se suas vantagens e desvantagens deste cultivo na opinião dos entrevistados, inclusive se os moradores possuem alguma espécie arbórea (árvore) em frente à casa e se desejariam plantar. Quais espécies indicariam para ser plantada na comunidade. Abordou-se também quais as dificuldades que eles encontram para cuidar de árvores.

Utilizou-se do método da observação ativa (APPOLINÁRIO, 2009), para realizar o levantamento da infraestrutura urbana, verificou-se a presença ou não de calçada, suas condições de conservação; se a rua é adequada ao trafego de pedestres e automóveis; se é pavimentada e se há espaço disponível para o plantio de uma árvore.

Numa última etapa entrevistou-se profissionais que lidam com a área de silvicultura, engenheiros florestais, que detém experiência em arborização no semiárido brasileiro para indicar as espécies para a área de estudo e demais informações referentes ao tema na área urbanizada.

\section{Procedimentos para análise dos dados}

A partir dos dados coletados, as respostas objetivas foram agrupadas analisadas com auxílio da estatística descritiva, utilizando planilha eletrônica, Excel da Microsoft ano 2010. Para as questões subjetivas as mesmas foram reunidas por similaridade e, quando possível, realizada a contagem da repetição de respostas idênticas, seguidos de discussão, e finalmente, apresentadas alternativas para minimização das dificuldades identificadas.

\section{RESULTADOS E DISCUSSÃO}

\section{Características socioeconômicas}

Dentre os 57 entrevistados, 75\% eram do gênero feminino, apresentaram idade média de 34 anos. Este alto índice deve-se a maior presença das mulheres no ambiente doméstico, durante o dia. Segundo o Estudo Censitário da População Quilombola da Paraíba (AACADE, 2012), a média de idade nas comunidades é de 27,8 anos, enquanto que a média nacional para a população em geral, segundo o censo do IBGE (2015) é 31,3 anos. Esta informação 
fornecida pelas integrantes do gênero feminino, é um fator positivo, pois os cuidados domésticos estão sob sua responsabilidade, incluindo atividades de jardinagem e arborização, inclusive é uma atividade destinada à população adulta.

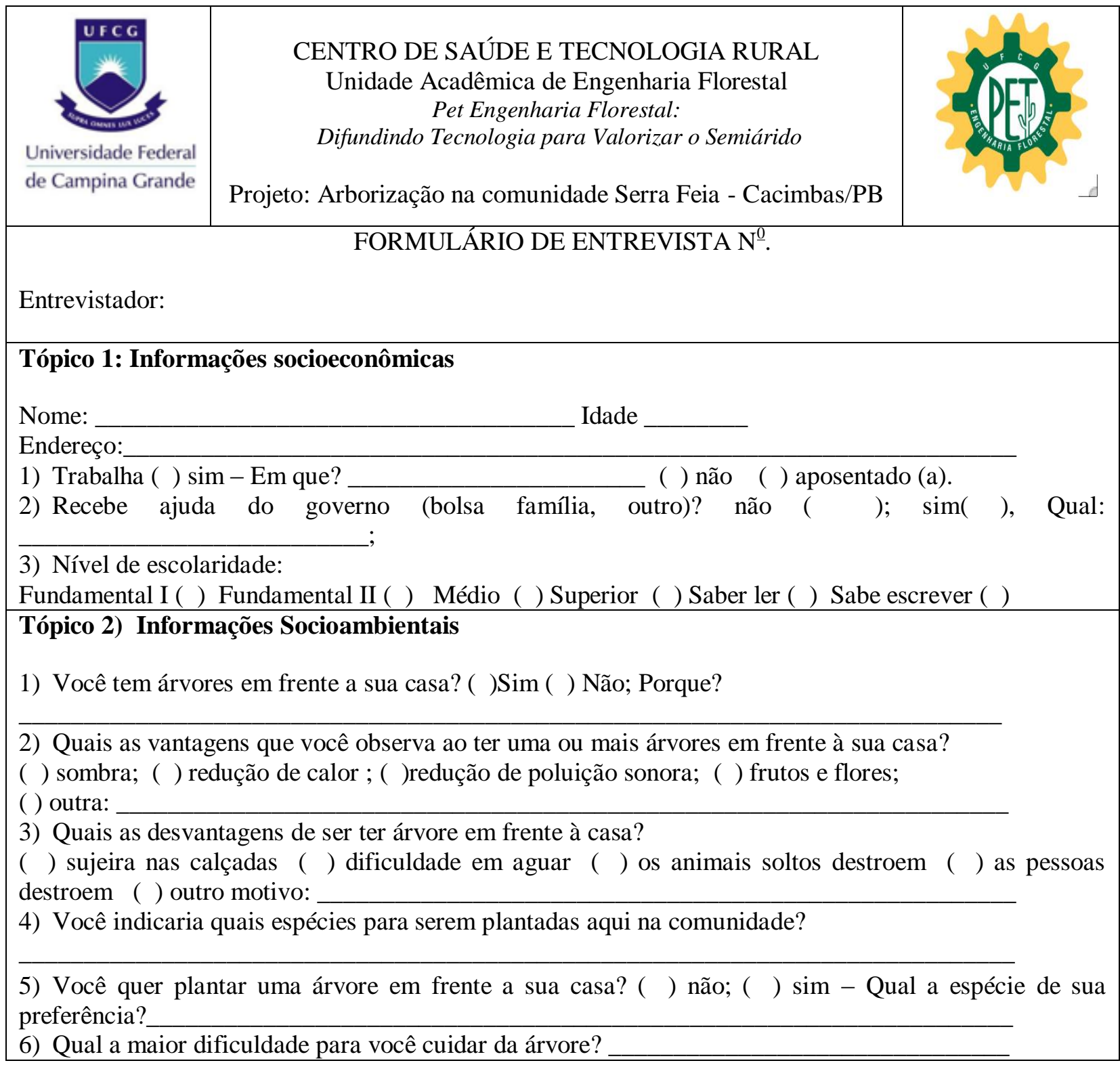

Figura 2. Questionário semiestruturado aplicado na comunidade Serra Feia, Município de Cacimbas-PB Figure 2. Semi structured questionnaire applied to community Serra Feia, Municipality of Cacimbas-PB

Cada família, em média, se constitui de quatro integrantes. A taxa de analfabetismo nas comunidades quilombolas da Paraíba é de 30,7\%, (AACADE, 2012). No Nordeste, o índice de analfabetismo chega a 16,6\%, e no país 8,3\% entre jovens acima de 15 anos (IBGE, 2015). $\mathrm{Na}$ comunidade pesquisada $14 \%$ dos entrevistados relataram que nunca estudaram e não sabem ler ou escrever. As dificuldades de acesso à escola, as limitações financeiras, a falta de estímulo ao aprendizado formal são entraves ao processo de escolarização das comunidades 
pobres, entretanto, comparando-se o índice obtido para esta comunidade em relação à média nacional para as comunidades quilombolas, pode-se afirmar que o índice corresponde à metade do verificado em nível nacional para tais comunidades. Este dado indica o quanto os pesquisados estão aptos à interpretarem informações referentes à importância da arborização no entorno de suas residências.

Embora a média de escolaridade seja próxima à brasileira, como um todo, as condições de vida são muito difíceis, cerca de $73 \%$ dos atores sociais relataram receber alguma ajuda de programas governamentais (bolsa família), o que evidencia a carência e a dependência das famílias de políticas públicas assistenciais. Na Paraíba as comunidades quilombolas dependem em cerca de 74\%, deste benefício (AACADE, 2012).

Segundo o IBGE (2015), o índice de desemprego no segundo trimestre de 2015, foi de $8,3 \%$, números inferiores aos $22,8 \%$ encontrado na comunidade de Serra Feia, segundo as respostas dos entrevistados que se designaram desempregados. A principal atividade mencionada foi a agricultura (64\%), inexiste atividade do setor secundário. Diante desta resposta é importante destacar que a comunidade se situa num planalto, circundada por serras que são divisores de águas de duas sub-bacias Piranhas-Açu e Taperoá, ambas na Paraíba. Área de difícil acesso. Soma-se a isto, as condições edafoclimáticas limitantes para uma agricultura intensiva. A energia utilizada na agricultura corresponde à força humana, o que acarreta, por um lado, menos danos aos solos, por outro, baixa capacidade de expansão das áreas utilizadas. Considerando a inexistência de medidas de conservação dos solos, tais como, plantio em curvas de nível, terraceamento; pois a área tem alta susceptibilidade ao processo erosivo, devido ao relevo acidentado, a agropecuária é desenvolvida de forma rudimentar e causa impactos negativos ao meio ambiente.

Observou-se a presença de esgoto a céu aberto, embora alguns fatores dificultassem esta constatação: o período de coleta dos dados ocorreu na época seca e a região estar submetida à alta evaporação devido às altas temperaturas que ocorrem na região semiárida brasileira.

Quanto ao desenho urbano, preponderam vias de trânsito de veículos e calçadas não pavimentadas. As ruas centrais permitem a passagem de veículos automotores, porém as ruas marginais são estreitas e íngremes, permitindo apenas locomoção a pé, no lombo de animais ou pilotando moto. As casas têm uma estrutura construtiva de duas águas, sem recuo, inexiste varanda ou jardins, como pode ser observado na Figura 3, que apresenta aspectos visuais da área. 


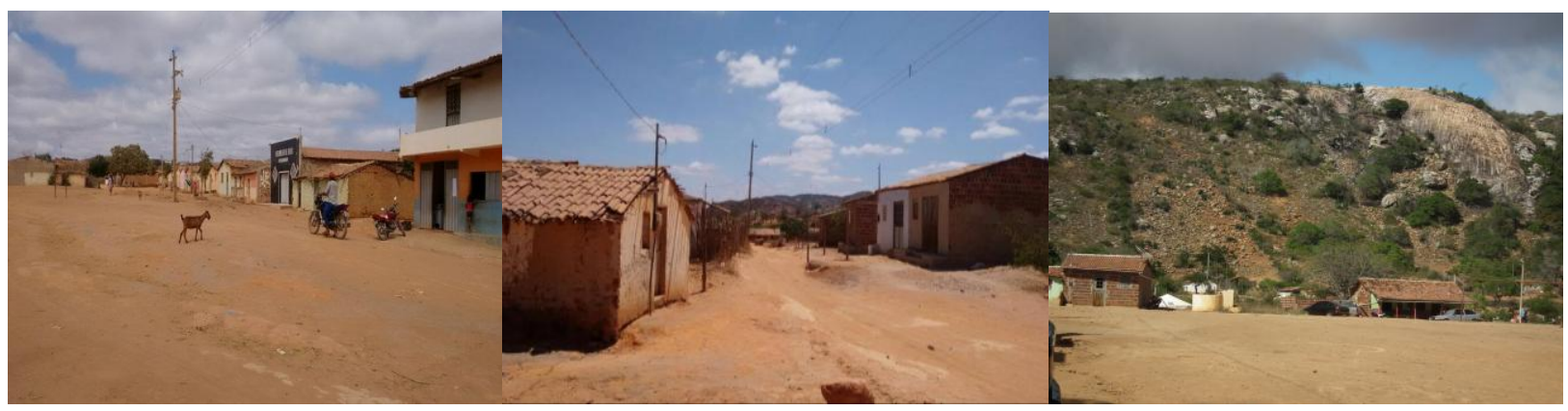

Figura 3. Aspecto visual da localidade, onde se observa vias não pavimentadas e casas de duas águas Figure 3. Visual aspect of the locality, where it is observed the lack of constructive structures and paving

\section{Características da arborização}

De um modo geral no setor das moradias existem poucas árvores, há exceção das áreas de serras onde se encontra resquícios de mata e se cultiva cajueiros e goiabeiras. Observou-se em $38,6 \%$ das residências visitadas a presença de árvores. O principal motivo apresentado para a ausência de árvores defronte suas residências, foi não ter condição financeira para a compra (20\%) e o mesmo percentual afirmou que os bodes e cabras as destroem pois, os animais são criados soltos. Em segundo lugar, veio a dificuldade em transportar a muda da árvore da cidade para comunidade (13,3\%). Quanto à primeira e a última justificativa, justifica-se devido às escassas condições financeiras para aquisição de mudas, no caso se for em grandes quantidades, mas em pequenas quantidades é possível o morador produzi-las, por esta ser uma área rural, favorecendo a produção de mudas.

Em sequência, apontou-se a seca $(7,1 \%)$ como um dos fatores que dificultam o plantio, ou a falta de espaço para plantar (7,1\%). Não ter interesse em plantar $(3,6 \%)$, outros justificaram a dificuldade para protege-la com grades $(1,8 \%)$, também que vândalos da própria comunidade a destroem (1,8\%), não sentem necessidade de cultivar uma árvore (1,8\%), pois já existe vegetação no entorno; ou, reside há pouco tempo no local e não teve oportunidade $(1,8 \%)$ de fazer o plantio. Em pesquisa realizada por Souza, Cardoso e Silva (2013), na cidade de Alegre-ES, obtiveram que os entrevistados desfavoráveis à arborização justificaram, sobretudo, que as árvores trazem sujeira. Precisamos destacar que a "sujeira" que a árvore produz são as folhas, que é um material biodegradável, inclusive pode ser utilizada na cobertura e proteção do solo, ou se transformar em composto orgânico.

Apesar das dificuldades apresentadas pelos entrevistados, todos demonstraram interesse em plantar uma árvore em frente à sua casa, desde que as condições fossem oferecidas, entretanto esta unanimidade é questionável, pois alguns disseram não ter interesse em plantar árvores. Em estudo semelhante, na cidade de Visconde do Rio Branco- MG, a 
maioria dos entrevistados (95\%) se mostraram favoráveis a arborização em praças e ruas (SILVA et al., 2014).

Quanto às vantagens que a árvore pode oferecer, obteve-se como resposta que elas oferecem sombra, frutos, flores, beleza, ajudam ao meio ambiente, além dos animais usarem como abrigo ou alimento. Segundo pesquisa realizada por Silva et al. (2014), em Visconde do Rio Branco - MG, a grande maioria dos entrevistados (71\%) mencionaram a sombra como benefício da arborização, além da preservação da biosfera (20\%), redução de impacto de chuva (6\%) e (3\%) diminuição do ruído.

Do mesmo modo, Souza; Cardoso; Silva (2013), afirmam que na cidade de Alegre-ES, em pesquisa realizada no centro da cidade e no bairro Guararema, 92\% dos entrevistados demostram compreender o significado positivo da árvore para a qualidade de vida, associando paisagem arborizada com a aproximação com a natureza, diminuição de incidência solar, sombreamento; redução na concentração de dióxido de carbono $\left(\mathrm{CO}_{2}\right)$, redução da poluição e a relação da arborização com as mudanças climáticas. Comparando-se estas respostas, podese observar que a percepção da importância da arborização na comunidade estudada é bem preliminar.

Pode-se acrescentar que, as árvores geram a sensação de bem-estar, atuando principalmente nos aspectos sociais e psicológicos. Influência o estado de ânimo dos indivíduos criando um ambiente agradável, para prática de atividades físicas, também reduz a poluição sonora, além de notável beleza estética (CRUZ; BEVILAQUA; ARRUDA, 2012)

Ao serem questionados sobre quais espécies que eles prefeririam plantar em frente as suas casas citaram as espécies apresentadas na tabela 01. As preferencias foram: Azadirachta indica, Mangifeta indica e Ficus carica. Todas espécies exóticas e apenas uma espécie frutífera, mas se destacam pela copa fechada, gerando bom sombreamento. Para auxiliar na interpretação dos dados obtidos e fundamentar a discussão, entrevistou-se a profa. Dra. Assíria Maria Ferreira da Nóbrega, do curso de Engenharia Florestal/Universidade Federal de Campina Grande, a mesma destacou que um dos objetivos da arborização é sombreamento, portanto deve-se escolher árvores com uma copa mais fechada. A pesquisadora citou as seguintes espécies, que se adaptam bem às condições do semiárido e que poderiam ser plantadas: Caesalpinia ferrea (jucá), Anadenanthera columbruina (angico), Spondias tuberosa (umbu) e Mangifera indica (manga). Relatou inclusive a importância da criação de pomares, em áreas pré-selecionadas e sugere cultivar Tamarindus indica (tamarindo), Anacardium occidentale (caju), Psidium guajava (goiaba), Spondias mombin (cajá), dentre outras frutíferas adaptáveis. Comparando-se os resultados obtidos com a posição da pesquisadora, observa-se que coincidiu o cultivo da manga, caju e da goiaba. A manga desenvolve uma grande copa, 
porém é mais exigente em água, por isto seu cultivo geralmente ocorre nos baixios. As plantas nativas devem ser incentivadas pela sua adaptação às condições ambientais.

Tabela 1. Espécies arbóreas que os moradores têm interesse em plantar na frente de suas casas. Comunidade Serra Feia, município de Cacimbas-PB

Table 1. Tree species that the residents find interesting to plant in front of their houses. Serra Feia community, Cacimbas-PB town

\begin{tabular}{lcc}
\multicolumn{1}{c}{ Nome científico } & Nome vulgar & Frequência absoluta \\
& & $(\%)$ \\
\hline Anacardium occidentale L. & cajú & 3,6 \\
Azadirachta indica A. Juss & nin-indiano & 14,3 \\
Citrus Sinensis L. Osbeck & laranja & 5,3 \\
Ficus carica L. & ficus & 7,2 \\
Mangifera indica Linn & manga & 14,3 \\
Mimosa tenuiflora (Mart.) Benth. & jurema-preta & 1,8 \\
Prosopis juliflora (Sw) DC. & algaroba & 1,8 \\
Psidium guajava L. & goiaba & 3,6 \\
Tabebuia alba (Chamiso) & ipê & 1,8 \\
Tabebuia caraíba Marth. & craibeira & 1,8 \\
Terminalia catappa L. & castanhola & 3,5 \\
\hline
\end{tabular}

Para auxiliar na interpretação dos dados obtidos e fundamentar a discussão, entrevistou-se a profa. Dra. Assíria Maria Ferreira da Nóbrega, do curso de Engenharia Florestal/UFCG, a mesma destacou que um dos objetivos da arborização é sombreamento, portanto deve-se escolher árvores com uma copa mais fechada. A pesquisadora citou as seguintes espécies, que se adaptam bem às condições do semiárido e que poderiam ser plantadas: Caesalpinia ferrea (jucá), Anadenanthera columbruina (angico), Spondias tuberosa (umbu) e Mangifeta indica (manga). Relatou inclusive a importância da criação de pomares, em áreas pré-selecionadas e sugere cultivar Tamarindus indica (tamarindo), Anacardium occidentale (caju), Psidium guajava (goiaba), Spondias mombin (cajá), dentre outras frutíferas adaptáveis. Comparando-se os resultados obtidos com a posição da pesquisadora, observa-se que coincidiu o cultivo da manga, caju e da goiaba. A manga desenvolve uma grande copa, porém é mais exigente em água, por isto seu cultivo geralmente ocorre nos baixios. As plantas nativas devem ser incentivadas pela sua adaptação às condições ambientais.

Quanto às espécies exóticas invasoras mencionadas pelos entrevistados, deve-se ter cuidado ao adotá-las pois, ao encontrarem condições favoráveis edafoclimáticas, incluindo a ausência de predadores, que são fatores que favorecem sua expansão, às vezes em 
detrimento das plantas nativas que não conseguem se manter, sobretudo se o ecossistema sofre com a ação antrópica, opinião corroborada por Martins (2012). No entanto, plantas exóticas também trazem benefícios, por exemplo, a Azadirachta indica (nin-indiano), citado pelos entrevistados, é empregado no controle de insetos, fungos e nematóides, também utilizado na indústria de cosméticos, fertilizantes, adubo, na produção de biomassa em propriedades rurais, reflorestamento e uso veterinário (RICKLI et al., 2011).

Comparando-se as observações da professora pesquisadora e as condições identificadas na comunidade, importante observar a largura das ruas de modo que as árvores não inviabilizem o tráfego de automotores.

Quanto às espécies citadas nos questionários, principalmente as frutíferas, o professor Dr. João Batista Alves (UFCG), em entrevista, indicou Anacardium occidentale e Spondias tuberosa, que são bem resistentes à seca, entretanto não deve realizar o plantio sem uma análise das condições de cada local selecionado.

\section{Infraestrutura urbana}

A infraestrutura urbana abrange vários elementos indispensáveis para a estruturação e o desenvolvimento dos aglomerados humanos. Se as efetividades dos serviços de abastecimento de esgotos, de água, de fornecimento de energia forem comprometidos, isso irá refletir não só nas configurações do espaço urbano, mas também nas condições de desenvolvimento econômico e na saúde e bem estar dos envolvidos. O acesso a tais serviços básicos, são indispensáveis quando se trata de qualidade de vida das populações urbanas, incluindo as condições de inclusão ou exclusão social. Há o fornecimento de energia elétrica e a água disponibilizada vem por meio de "tratores-pipa".

Sobre as condições do meio físico para o cultivo de árvores, o Professor Dr. João Batista Alves, do curso de Engenharia Florestal/UFCG, assevera que o plantio de árvore para arborização no semiárido requer muitos cuidados, aqui temos solos rasos, afloramentos rochosos e isso faz com que o sistema radicular das plantas se expandam na horizontal, por isto é preciso diagnosticar as condições de solo muito bem. Deve-se atentar quanto à presença da fiação elétrica. Quando são árvores de grande porte, deve-se plantá-la a $5 \mathrm{~m}$. de distância da construção, inclusive, considerar que as raízes podem danificar a calçada se não for respeitada a distância mínima. Por exemplo, caso os moradores optem por nativas, como Handroanthus impetiginosus nome do descritor da espécie (ipê-roxo), de médio porte, o mesmo poderia ser plantado há uma distância de $3 \mathrm{~m}$ da construção.

Deve-se estar atento a infraestrutura do lugar e seguir alguns parâmetros técnicos como sugere Carielo (2012), para às árvores ofertarem todos os seus benefícios ao ambiente 
em que se encontra, deve-se construir um canteiro com no mínimo $1 \mathrm{~m}^{2}$ para permitir a infiltração de água e evitar rachaduras nas calçadas; fazer a escolha da espécie adequada, principalmente quando estiver sob a fiação elétrica; além de amparar a planta com tutor no início do seu desenvolvimento. O tutor tem a função de conduzir o tronco para deixá-lo retilíneo. As árvores nas calçadas devem permitir o trânsito de cadeirantes, segundo Silva; Fidelis; Ferreira e Castro (2011), entre a árvore e a murada deve haver uma distância mínima de $1,20 \mathrm{~m}$.

Identificou-se que, em 89,3\% das residências não há calçada. Inclusive, os pedestres transitam na mesma via dos automóveis e caminhões. Em apenas $(36,8 \%)$ das residências com calçadas elas estão alinhadas e favorecem o deslocamento das pessoas. As ruas não têm pavimentação, são de barro compactado e em alguns casos apresentam pedregosidade $(3,5 \%)$ ou rochosidade $(3,5 \%)$.

\section{A limitação hídrica na região é um empecilho ao plantio de árvores}

A água é um bem natural fundamental para atender as necessidades vitais, sua disponibilidade ou escassez influi decisivamente na qualidade de vida dos seres humanos (BACCI; PATACA, 2008). Com base nesse aspecto, a população do semiárido nordestino enfrenta problemas com disponibilidade de água, gerado pelo regime pluviométrico que apresenta longos períodos de estiagem. As medidas implementadas, atualmente, não são suficientes para garantir o fornecimento de água de qualidade e com regularidade para as populações "rurbanas", e que tem se agravado a cada ano (SANTOS; SANTOS; SANTOS, 2014).

A comunidade Quilombola Serra Feia por estar situada no semiárido, onde há limitação hídrica, precisa identificar mecanismos para irrigar as mudas implantadas após o plantio no campo, o reaproveitamento de água é uma alternativa.

Existem diversos métodos de irrigação, sendo o mais indicado para as condições de escassez de água o gotejamento, pois trata-se de um sistema que preza pela distribuição de água de maneira uniforme, inclusive buscando alternativas de baixo custo que se adeque à realidade local (RIBEIRO et al., 2012).

Entretanto diante das condições limitantes desta comunidade, uma importante alternativa é a utilização de águas residuais, embora tais estudos estejam em fase inicial, Barroso e Wolf (2011) realizaram um levantamento bibliográfico, de dez anos de pesquisas, apresentando os resultados para o desenvolvimento das culturas e as alterações nas condições dos solos, principalmente para as regiões semiáridas brasileiras, necessitando-se atentar para evitar o contato da água com as partes da plantas que serão consumidas, 
especialmente in natura, que técnicas serão utilizadas para aplicação das águas resultantes da lavagem de pratos e banho, e controlar a salinidade, sodicidade e alcalinidade do solo. No caso em estudo a aplicação será pontual para a manutenção de mudas arbóreas simplificando as preocupações quanto à saúde humana.

A ausência de estudos semelhantes em outras comunidades de baixa renda dificultou a comparação dos resultados, entretanto estes dados auxiliaram a construir algumas ações extensionistas voltadas ao aprofundamento nos conhecimentos sobre arborização e poda de árvores no semiárido brasileiro. A dificuldade em fazer um programa intensivo de reeducação para um ambiente mais arborizado foi a falta de recursos financeiros para levar à frente um projeto arrojado de fornecimento das mudas, da adubação, da grade de proteção, sem desconsiderar as condições precárias de infraestrutura urbana.

\section{CONCLUSÕES}

Os entrevistados destacaram que as maiores vantagens da arborização são a sombra, as flores e os frutos. Dentre os que não possuem árvores na frente de suas residências as três maiores justificativas foram: a falta de condições financeiras para a compra, a presença de herbívoros que destroem as mudas, sobretudo bodes e cabras, e a dificuldade de transportar a muda da cidade para o campo. Todos aceitaram plantar árvores em frente à sua casa, caso fossem dadas condições para implantá-las e preferiram Mangifera indica (mangueira) e Azadirachta indica (nin-indiano).

Avaliando-se infraestrutura local para implantação de arborização, como medida de atenuação do microclima, a largura das ruas é o maior empecilho, seguido do solo compactado que predomina na área, os animais que são criados soltos, pisoteiam ou alimentam-se das mudas. Para um projeto de arborização das ruas ser bem-sucedido faz-se imprescindível realizar o plantio com grades protetoras, reuso de água, compromisso da comunidade em zelar e irrigar a muda nos períodos secos.

\section{AGRADECIMENTOS}

Agradecemos à comunidade que prestimosamente nos forneceu às informações solicitadas, sem as mesmas seria impossível este estudo. À Universidade Federal de Campina Grande por propiciar as condições de desenvolvê-la e as bolsas de estudo fornecidas pelo Programa de Educação Tutorial do Ministério da Educação (PET/MEC). 


\section{REFERÊNCIAS}

AACADE. Associação de Apoio aos Assentamentos e Comunidades Afrodescendentes. Estudo Censitário da População Quilombola da Paraíba. João Pessoa, 2012. Disponível em:<http://quilombosdaparaiba.blogspot.com.br/2014/12/estudo-censitario-das-

comunidades.html>. Acesso em: 27 dez. 2016.

APPOLINÁRIO, F. Metodologia da ciência: filosofia e prática da pesquisa. São Paulo: Cengage Learning, 2009. 209 p.

BACCI, D. de La C.; PATACA, E. M. Educação para a água. Estudos Avançados, São Paulo, v. 22, n. 63 , p. 211-226, 2008.

BARROSO, L. B; WOLF, D. B. Reuso de esgoto sanitário na irrigação de culturas agrícolas. Engenharia Ambiental, Espírito Santo do Pinhal, v. 8, n. 3, p. 225-236, 2011.

CARIELO, P. Avaliação da arborização urbano do bairro "Parque Castelo Branco" do município de Presidente Prudente - SP. Colloquium Agrariae, Foz do Iguaçu, v. 8, n. Especial, p. 46-54, 2012.

COMPANHIA DE PESQUISA DE RECURSOS MINERAIS - CPRM. Projeto cadastro de fontes de abastecimento por água subterrânea estado de Paraíba. Diagnóstico do município de Cacimbas. Ministério de Minas e Energia. Recife Setembro/2005. Disponível em: http://rigeo.cprm.gov.br/xmlui/bitstream/handle/doc/15888/Rel_Cacimbas.pdf?sequence=1 . Acesso em: 20 dez. 2016.

CRUZ, B. M. Procedimentos metodológicos para avaliação da arborização urbana na cidade de São Paulo. Paisagem e ambiente: ensaios, São Paulo, n. 31, p. 25-60, 2013.

CRUZ, D. C. A.; BEVILAQUA, L. C.; ARRUDA, G. O. S. F. Diagnóstico da arborização da Avenida Plínio Arlindo de Nês, município de Xanxim, SC. Unoesc e Ciência, Joaçaba, v. 3, n. 2, p. 147-156, 2012.

INSTITUTO BRASILEIRO DE GEOGRAFIA E ESTATÍSTICA - IBGE. Panorama das cidades, 2015. Disponível em: <https://cidades.ibge.gov.br/brasil/pb/cacimbas/panorama>. Acesso em: 31 out. 2017.

LEAL, L.; BIONDI, D.; BATISTA, A. C. Influência das Florestas urbanas na variação termohigrométrica da área intra-urbana de Curitiba-PR. Ciência Florestal, Santa Maria, v. 24, n. 4, p. 807-820, 2014.

MARTINS, N. F. A Dinâmica da predação entre Sus scrofa (Predador) e a Casearia sylvestris (Presa) na Região do Pontal. UNICIÊNCIAS, Cuiabá, v. 16, n. 1, p. 51-55, 2012.

MEDEIROS, A. C. de; LIMA, V. L. A.; TAURA, T. A.; SILVA, A. de S. Índice de priorização tecnológica: estudo de caso em comunidades quilombolas do estado da Paraíba. Revista Brasileira de Geografia Física, Recife, v. 8, n. 4, p. 1125-1141, 2015.

OLIVEIRA, K. A; CORONA, H. M. P. A percepção ambiental como ferramenta de propostas educativas e de políticas ambientais. Revista Científica Anap Brasil, Alta Paulista, v. 1, n. 1, p. 53-72, 2008. 
RIBEIRO, P. A. A.; TEIXEIRA, M. B.; COELHO, R. D.; FRANCO, E. M.; SILVA, N. F.; CARVALHO, L. C. C.; ALVES, M. E. B. Gotejadores submetidos a condições críticas de qualidade da água. Irriga, Botucatu, Ed. Especial, p. 368 - 379, 2012.

RICKLI, H. C; FORTES, A. M. T.; SILVA, P. S. S. da; PILATTI, D. M.; HUTT, D. R. Efeito alelopático de extrato aquoso de folhas de Azadirachta indica A. Juss. em alface, soja, milho, feijão e picão-preto. Semina: Ciências Agrárias, Londrina, v. 32, n. 2, p. 473-484, 2011.

ROCHA, J. S. M. da; Manual de projetos ambientais. Santa Maria, RS: Imprensa Universitária, 1997. 423 p.

SANTOS, A. R. R. dos; SANTOS, C. A. dos; SANTOS, A. R. dos. As relações de poder no semiárido nordestino. Revista Ambivalências, Aracajú, v. 2. n. 4 . p. 151 - 164, 2014.

SILVA, F. F. da; FIDELIS M. E. A.; FERREIRA E CASTRO, P. arborização e acessibilidade em calçada: comentários sobre o deslocamento entre o campi da Universidade Federal Fluminense. REVSBAU, Piracicaba, v. 3, n. 6, p. 43-63, 2011.

SILVA, R. V. da; REGO, A. M. T.; COSTA, T. S.; SILVA, D. G. da; TOSTES, R. B. Percepção ambiental dos moradores de Visconde de Rio Branco - MG, em relação à arborização urbana. REVSBAU, Piracicaba, v. 9, n. 3, p 108-121, 2014.

SOUZA, S. M; CARDOSO, A. L; SILVA, A. G. Estudo da percepção da população sobre arborização urbana, no município de Alegre-ES. REVSBAU, Piracicaba, v. 8, n. 2, p. 68-85, 2013. 